fact in relation to the plague in the time of Sydenham, such the character of the yellow fever as reported by Rush, and such was notoriously the case in the late singular peregrinations of the epidemic cholera. And, it is believed, such has been the controlling influence of all preceding epidemics. The idea, therefore, of "concomitant epidemics" is at best extremely paradoxical, if not an absurdity. It is what mathematicians call the occupancy of the same space at the same time by two bodies, which they regard physically impossible.

Celsus advised women to be treated after delivery as though they had received some wound in an important organ or part of the body; and Willis says, "women in child-bed ought to be managed not only as persons sorely wounded, but as having gotten a feverish disposition." These averments probably have foundation in matter of fact. The process of parturition leaves the interior surface of the uterus partially, at least, denuded. It is a species of wound. And experience bas too well shown, that wherever erysipelatous fever has prevailed, epidemically, most wounds or organic lesions have been the occasion of an attack of the prevalent disease. Puerperal lesions constitute no exception to the general results. Indeed, that this is the fact, appears demonstrated from some cases incidentally related by Dr. G. himself. In his sixth reported case, "on the fifth day" there was "a complete termination of the fever." The crisis was by a diarrhœa, accompanied with an erysipelas of one of the arms." In another case mentioned by him, the wife of $\mathrm{Wm}$. Walker, a crisis was formed by the appearance " of an erysipelas on the integuments of the abdomen." Dr. Gordon remarks (page 49), "a very frequent crisis of the disease is by an external erysipelas; which is a proof that there is a metastasis, or translation, of the inflammation from the internal to the external parts." 'This fact appears clearly to admit the identity of these affections, or the erysipelatous character of the puerperal fever of Aberdeen, else a change of character must have taken place in the metastasis.

[To be continued.]

\title{
THIMHLE IN THE UTERUS.
}

[Communicated for the Boston Mrdical and Surgical Journal.]

November 2nd, 1836, I was called to $\mathrm{M}$ rs. F., married woman, aged 30 , of a plethoric habit, who was suffering with severe pain in the back and lower part of the abdomen, accompanied with vascular and nervous excitement. Since the birth of her only child, who was three years old, she has had almost constant pain in the back. She has menstruated regularly, but with difficulty, having about every three months so much distress as to require medical attendance. She passer the last period without menstruating, and it was then near ber time. Venesection was succeeded by a rigor, and afforded no relief from pain. In order to ascertain the cause of this evidently uterine pain, $l$ made an examination per vaginam. The os tince was sufliciently dilated to adnit the point of the 
finger, which came in contact with a hard foreign substance. Upon extraction, with pocket-case forceps, it proved to be a steel thimble without a top. An injection into the vagina, of a strong solution of ext. hyoscyamus, and the adininistration of a cathartic, completed the treatment. She was entirely relieved of her old complaint, and in ten months and two days (Sept. 4h, 1837) was delivered of a healthy child.

Upon inquiring how the thimble came there, she stated that when her child was born she had a midwife with her, and remembered her inquiring for her thimble, when about to leave, and it was not to be found. It was undoubtedly the cause of her suffering for three years, and must have been introduced before the uterus had resumed its natural dimensions. From the fact that conception took place so soon after the removal of the thimble, we may infer that it prevented fruitfuluess, sither by preventing the ingress of the semen or by allowing the escape of the impregnated ovum. The position of the thimble was with its side presenting, and its roughness cnabled me to turn it so as to pass one blade of the forceps inside. To slow the importance of making examination, I will state that she had been attended, at different times during the three: years, by ten physicians, none of whon examined her per vaginam, and either one of whom might have given her permanent relief bad he known the cause of her suffering.

South Berwick, Me., March 18th, 1844.

E. Barteetr, $\mathrm{J}_{\mathrm{K}}$.

\section{RESULT OF AN OPERATION FOR THE CURE OF SPERMATORRHCEA.}

[Communicnted for the Boston Medical and Gurgicul Jourual.].

In the Ist No. of Vol. XXIX. of the Boston Medical and Surgical Journal, are the details of an operation performed by Dr. Josiah Crosby (formerly of this place, but now of Manchester. N. H.), upon a young gentleman for the cure of semiral weakness. The operation being no less than the entire removal of the testicles, was uovel in its nature, and undoubtedly unwarrantable as a general method of procedure in such cases. But, be that as it may, the results in this case have been highly gratifying, if we may judge from the great change which has been wrought in the condition of the patient by the operation. From being an utter outcast from society, almost completely demented, and destined apparently to the life of a miserable recluse, his very existence absolutely unknown to the nearest neighbors of the family, a complete metamorphosis has been effected both physically and mentally. lnstead of bein" little better than a drivelling idiot, as at the time of the operation, with just reason enough to implore anything which afforded him a chance of relief, he is now actively engaged in mereantile pursuits, witl mental vigor as well as physical capacity much above mediocrity. The first ray of light which lollows the removal of a congenital blindness, would elicit no livelier expressions of gratitude than the results of this operation do now call forth from the unfortunate subject of it. This, ton, 